\title{
PlantTwin simulation system as a tool for verifying production plans and supporting decision-making to improve the efficiency of machine-building industries
}

\author{
Petr A. Nikishechkin ${ }^{1,2, *}$, Sergey S. Ivashin ${ }^{1}$, Vitaly E. Chernenko ${ }^{3}$, Andrey A. Malykhanov ${ }^{3}$, \\ and Nikita V. Dolgov ${ }^{1}$
}

${ }^{1}$ LLC "Digital Systems Factory", Moscow, Russia

${ }^{2}$ MSUT "STANKIN", Moscow, Russia

${ }^{3}$ LLC "Amalgama", Ulianovsk, Russia

\begin{abstract}
The article deals with the issues of improving the efficiency of production and logistics systems (PLS) of machine-building enterprises through the joint use of MES/APS systems and simulation systems for verification of production plans and decision support. The possibility of using the PlantTwin simulation system on the example of a small machinebuilding enterprise is considered. Simulation of the operation of the enterprise's PLS when performing a given production program is performed. Based on the results of simulation modeling, a number of organizational and technological proposals and recommendations for improving the efficiency of the enterprise's PLS were formed. The proposed solutions were verified by making changes to the simulation scenario and obtaining new results showing their effectiveness.
\end{abstract}

\section{Introduction}

The main goal of any modern machine-building enterprise is to achieve maximum production efficiency; it is necessary that products of appropriate quality are produced in the appropriate time. Therefore, the tasks of planning, monitoring and evaluating the feasibility of the production plan are among the most important in the production. The first step in production planning is to prepare enlarged production plans [1,2]. At the next stage, operational planning is performed and a detailed production schedule is prepared with reference to specific divisions and technological equipment. Usually, planning tasks are solved using systems of the APS (Advanced Planning \& Scheduling Systems) and MES (Manufacturing Execution Systems) classes. Such operational planning systems have a number of indisputable advantages for their use and have wide capabilities: assessment of the possibility of implementing the production plan, drawing up detailed plans for equipment operation, coordinating production processes, analyzing productivity, and tracking products [3].

\footnotetext{
*Corresponding author: npa@digitalfabrika.ru
} 
However, such systems do not allow us to take into account a number of factors, including probabilistic ones, which are typical for any real production, such as equipment failures, repairs, transport restrictions, and others. At the same time, such factors can have a decisive impact on the timing and ability to complete a given production plan [4-6].

Thus, to increase the efficiency of production planning, it is necessary to use tools that allow modeling the behavior of the production system taking into account these factors and to verify the production schedule generated in MES/APS systems [1,3].

One of the ways to solve this problem is to use simulation systems. The main advantage of such systems is the ability to take into account a number of probabilistic and situational factors in modeling. Also, systems of this class allow to model the system behavior when changes in source data (for example, to test the impact of organizational and technological solutions for manufacturing and logistics system) necessary for more detailed and rapid analysis of data [7].

At the same time, the tasks of the simulation systems do not include creating a production schedule - these data are input for it, and the main task is to model production processes based on the initial data about the production and logistics system (PLS), but taking into account a wider range of factors. Thus, for the best synergistic effect, it is assumed that MES/APS and simulation system are used together to improve the efficiency of building a production plan and analyze the risks of its unattainability $[3,8,9]$.

The article discusses the PLS of a machine-building enterprise specializing in the production of gearboxes, which clearly demonstrates the possibilities of joint application of the MES/APS system and simulation system, as well as the results of such integration.

\section{Research of functional capabilities and determination of the set of necessary data for PLS modeling in the PlantTwin simulation system}

Currently, there is a wide range of simulation systems, among which we can distinguish such world leaders as: PlantSimulation (Tecnomatix Plant Simulation Tool) (Siemens, Germany), AnyLogic (The AnyLogic Company, USA), Arena (Rockwell Automation USA), DELMIA (Dassault Systèmes SE, France), and others.

To solve the problems described in this paper, the PlantTwin simulation system was chosen. The PlantTwin system has its own computing core developed by Russian specialists with extensive experience in the field of simulation. PlantTwin has broad functionality and includes three main modules: a scenario editor, a built-in planning module, and a simulation module.

The PlantTwin system allows you to perform simulations based on a production plan generated by both external systems and the built-in planning module, which is an important advantage of the system. The built-in planning module allows you to check the theoretical feasibility of a production program and generate a production schedule based on one of several planning strategies. This functionality is important because it is not always possible to generate a plan in third-party MES/APS systems when changing the input data of scenarios, for modeling "what if?" situations [7-10].

Input of source data for modeling in PlantTwin can be performed either through the internal interface of the script editor, or by importing a specialized download file in Excel format. The structure of this download file allows you to store all the necessary source data in the form of linked tables and, thus, create a scenario for modeling in offline mode, without using a software package.

At the first stage, data is entered about the structure of the enterprise, which is set in the form of a tree hierarchy of divisions. Then it describes a production facility types the 
existing production centres (PC) and the composition of production centers linked to the company's division. Entering PC types is necessary for grouping PC's that have the same characteristics, and further linking technological operations to them. Also, for each PC, information is entered about its work schedule, periods of unavailability, and repair schedules [10-13].

The transport system of an enterprise is described by entering links between the main elements of the PLS (production centers, storage devices).

The next step is to enter information about the products manufactured at the enterprise: structure and composition of parts and assembly units (PAU), route and technological manufacturing process, list of purchased components (PC) and their purchase schedules, initial stock of products, as well as the production plan for manufacturing products.

One of the fundamental differences between simulation systems and planning systems is the ability to take into account additional factors: situational and probabilistic. The PlantTwin system allows you to take into account the following additional factors that affect the operation of the PLS:

- time-varying execution time of technological operations;

- delays and deviations in the delivery time of components;

- different time of transportation of workpieces between the production units;

- limiting the filling capacity of buffers (warehouses, storage devices) at different stages of the production cycle;

- unscheduled PC repairs (emergency equipment failures) due to their failure;

- repairs of equipment by operating time.

Accounting for the above factors in operational scheduling systems is usually not carried out, but during production, these factors can have a significant impact on the implementation of the production plan [6-8].

\section{Application of the PlantTwin simulation system on the example of a small machine-building enterprise PLS}

Considered small machine-building enterprise specializes in mechanical processing and produces gearboxes. PLS of the enterprise has 30 units of technological equipment and has the following organizational structure:

1. Machining shop No. 1: procurement section, section of CNC machines, section of universal machines with manual control.

2. Mechanical processing shop No. 2: tooth processing section, grinding section, locksmith section.

3. Assembly shop: washing area, control area, Assembly area.

The company has an approved work schedule for both the company as a whole and its individual divisions: the entire company has approved a planned vacation schedule: in January; the CNC equipment section works in 2 shifts ( 5 days a week), all other divisions in 1 shift.

The reduction drive manufactured at the company consists of 50 items that can be divided into four groups:

- parts of own production (gears, shafts, caps, bushings, stopper, etc.);

- purchased components (PU): bolts, pins, washers, nuts, gaskets, bearings, etc.;

- parts, part of the operations for the production of which is implemented through external cooperation.

This is due to the fact that the company specializes in mechanical processing and does not have its own facilities for heat treatment. The execution of these operations in the manufacture of shafts and gears is transferred to external cooperation. 
- parts that are fully manufactured by external cooperation. These parts include the gearbox housing.

The following tasks are planned to be solved using the simulation system:

- perform simulation of the PLS operation based on the specified source data of the enterprise;

- evaluate the feasibility of the plan based on the initial data of the production and technological system of the enterprise, as well as probabilistic factors;

- the results of the simulations to analyse the work of PLS on the following criteria: the equipment load, the bottlenecks of the process chain, the production cycle, the reliability of PLS, etc.;

- the results of the analysis to form a number of organizational and technological proposals and recommendations for balancing and optimizing production;

- check the impact of the proposed recommendations on the operation of the PLS by making changes to the original scenario and performing its simulation.

In the presented example, according to the enlarged production plan, the task was set to produce 100 units of gearboxes in the period from 01.01.2020 to 04.06.2020. Using the built-in planning module, a detailed production schedule was generated, according to which the estimated production cycle for manufacturing 100 gearboxes was 110.93 days: the start date of the production cycle is 14.02.2020, the end date is 04.06.2020. Thus, according to the built schedule, the production program should be performed at $100 \%$.

Based on the initial data about the PLS and the generated detailed schedule, a simulation of the PLS operation was performed. Based on the results of the simulation, results were obtained on the implementation of the production program, taking into account all the specified probabilistic and situational factors. The obtained simulation results showed that with the planned start date of the production cycle, the end date of the production cycle is shifted to 08.06 .2020 . According to the simulation results, 85 gearboxes were produced by the specified production date, which is $85 \%$ of the specified plan. The remaining $15 \%$ of products were produced with a 4-day delay due to the fact that when developing the schedule, the APS system did not take into account a number of additional factors, namely: non-constant time of performing operations for moving parts in the course of the technological process between workplaces, emergency equipment failures, routine repairs and maintenance on equipment operating time, etc.

Based on the results of the simulation, data were obtained for analyzing the operation of the production and logistics system. Important output indicators include the equipment load factor, which determines how busy this equipment is when performing work $[11,12]$. This indicator is calculated both at the planning stage and based on the results of modeling. At the same time, the average value of the equipment load factor for the entire simulation period does not allow us to fully determine the picture of equipment loading, since the equipment may not constantly participate in the production process, or it may have a low load factor for one production period and be overloaded at another [13-15].

The simulation system makes it possible to conduct a more detailed analysis and estimate the equipment load over a set period, for example, with a monthly interval (Fig. 1). 


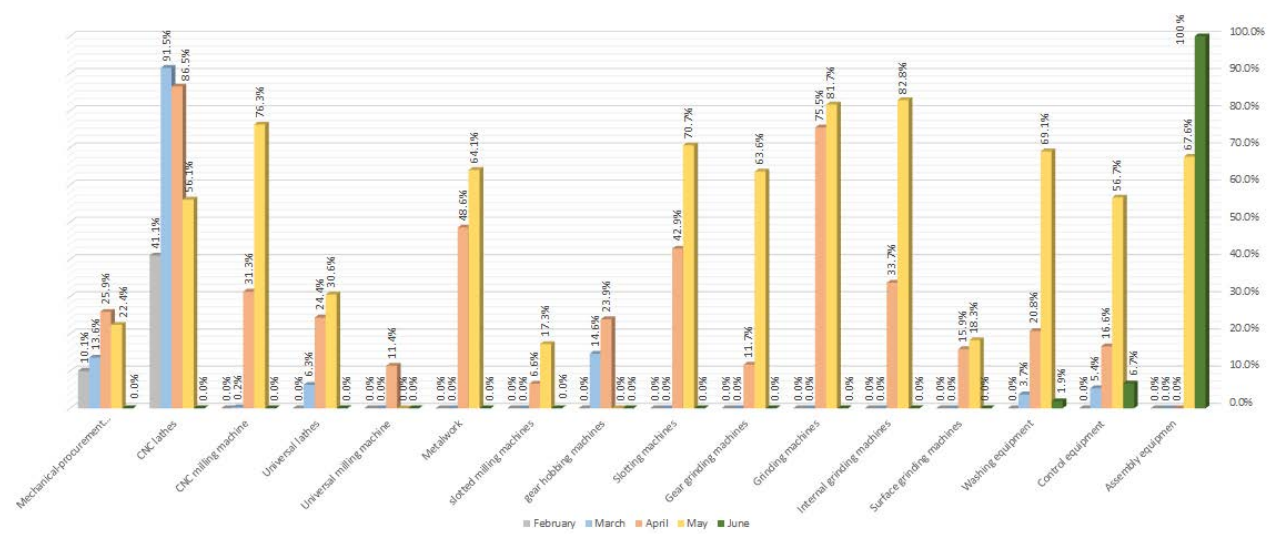

Fig. 1. Chart load chart by month.

In addition, the PlantTwin system allows you to simulate the occurrence of failures and subsequent repair (restoration) of equipment based on the available statistics of failures and emergency repairs. Based on the simulation results, the reliability of the PLS operation was analyzed based on the assessment of the frequency of equipment failure. The diagram of the time of repair of production centers (Fig. 2) clearly shows the low level of reliability of slotted milling and gear milling equipment.



a)

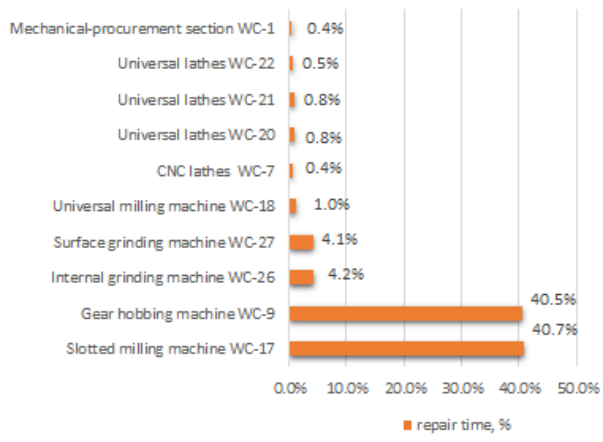

b)

Fig. 2. Diagram of equipment repair time: a) repair time in hours, b) percentage of the ratio of repair time to the working time Fund.

Based on the results of the analysis of the simulation output data, the following features of the work analyzed by the enterprise's PLS can be identified:

- the group of CNC lathes working in 2 shifts has a fairly high equipment load factor in March and April, and the group of universal lathes working in 1 shift has a low equipment load factor;

- the group of CNC milling machines has a low equipment load factor, as well as the group of slotted milling and gear milling equipment. However, the latter group has low reliability (due to frequent emergency failures)

- the group of universal milling machines has a low equipment load factor.

Thus, critical groups of equipment with unbalanced loading were identified: turning, CNC cutting, CNC universal lathes, universal milling, spline -, gear hobbing.

Based on the results of the analysis, the first group of organizational and technological solutions was developed:

1. Set a group of universal lathes as an alternative type of equipment for performing operations performed on $\mathrm{CNC}$ lathes. The execution time for these 
operations on universal lathes will be longer, but the implementation of this solution will allow you to balance the load of groups of lathes.

2. Completely transfer the operations performed on the groups of gear milling and slotted milling equipment to the group of CNC milling machines. This solution will increase the reliability of the production and logistics system, completely eliminating machines with a low degree of reliability and increase the load factor of equipment for $\mathrm{CNC}$ milling machines.

3. Change the schedules of equipment groups. Change the working schedule of the group of CNC lathes from 2 shifts to 1 shift and additionally introduce a 6-hour working Saturday. Change the working schedule of CNC milling machines from 2 shifts to 1, extended, 10-hour shift and additionally enter a 6-hour working Saturday.

Based on the results of experiments with the initial data modified in accordance with the recommendations, the following positive changes in the functioning of the PLS were revealed:

- the number of finished products produced on schedule increased from $85 \%$ to $97 \%$;

- the entire order was 5 hours behind schedule;

- modeled the transfer of the enterprise from 2-shift operation to 1-shift operation by changing the work schedule of groups of CNC equipment. This solution will allow you to increase The equipment load factor and reduce the costs associated with the second shift of the enterprise;

- the change in the company's work schedule has led to a more complete load of the group of universal turning equipment and $\mathrm{CNC}$ milling equipment;

- balanced loading of a group of $\mathrm{CNC}$ and manual turning equipment by introducing alternative routes;

- increased reliability of the PLS by eliminating equipment with a low probability of failure-free operation (gear milling and slotted milling).

Figure 3 shows changes in the comparative hardware load schedule by month. 


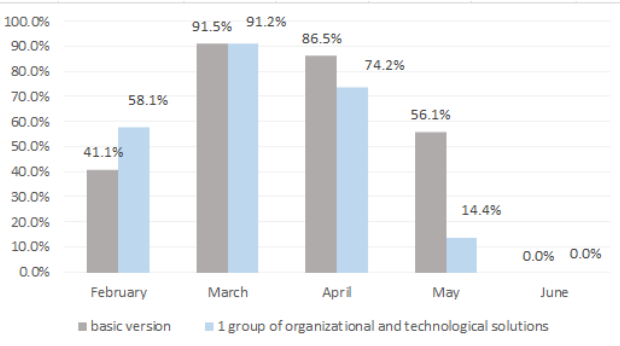

a)

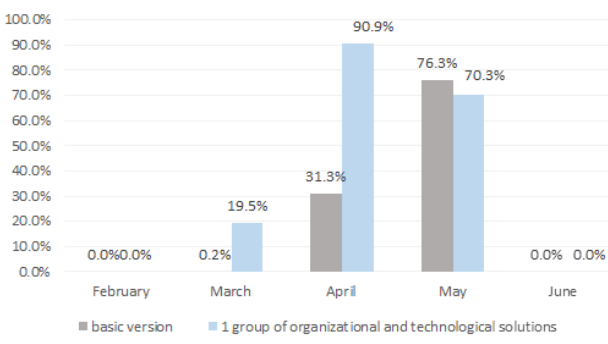

c)

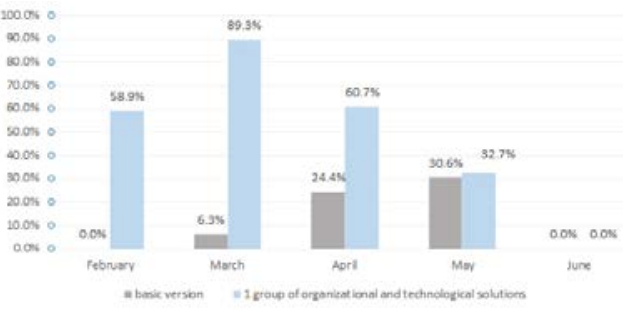

b)

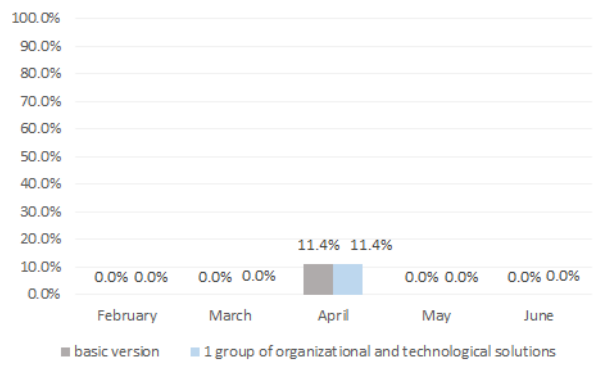

d)

mbasic version $\quad 1$ group of organizational and technological solutions

Fig. 3. Comparative schedule of equipment loading by month: a) group of CNC lathes, b) group of CNC milling machines, c) group of universal lathes, d) group of universal milling machines

Despite the organizational and technical solutions proposed and confirmed by the simulation model, the group of universal milling equipment also remains little used. To reload this group of equipment, based on the analysis of the product composition, a second group of organizational and technological solutions was formed, which consists in transferring a number of nomenclature items of purchased components for production at the enterprise's own facilities. From the General nomenclature of purchased components, groups of products were selected for the production of which no purchase of new equipment is required, namely: pins, keys, nuts, and washers. At the same time, taking into account the technological process of production of nuts and washers and the capabilities of the enterprise, the implementation of electroplating operations is transferred to external cooperation.

Modeling of the second group of organizational and technological solutions was carried out in stages (table 1), with experiments after the transfer to production of each of the purchased components groups: pins, keys, nuts, washers.

After translating the nomenclature of pins, dowels and nuts, the following result was obtained: production output on time was $95 \%$, the production program lag is 5 hours, and the load of the group of universal milling equipment increased by $37 \%$ during the modeling period (figure 4). 


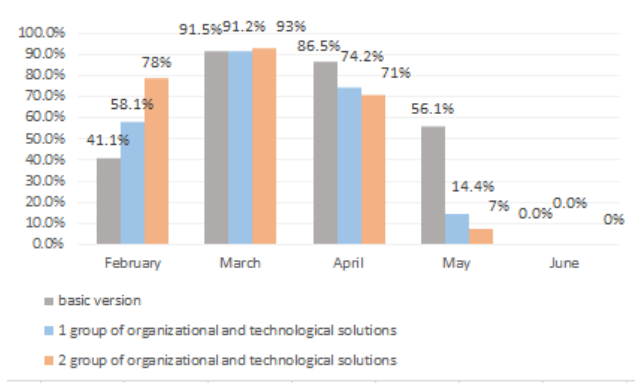

a)

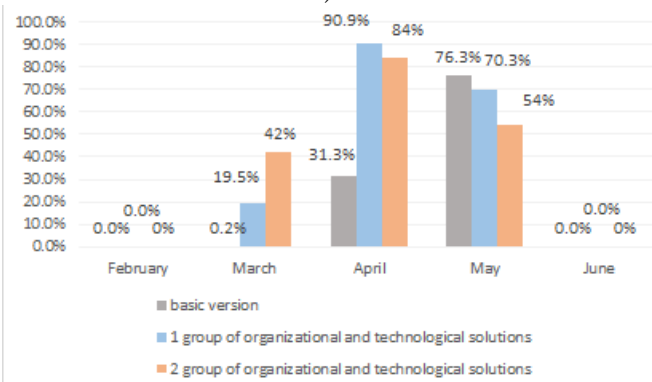

c)



b)

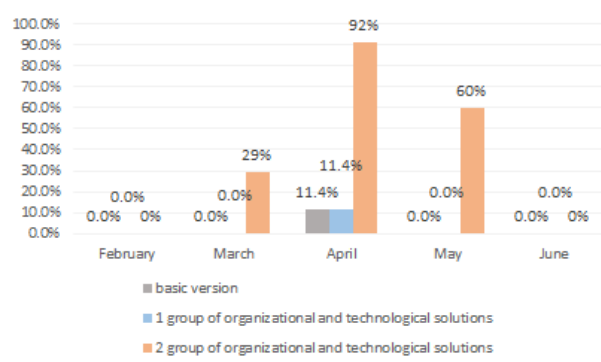

d)

W basic version $\quad$ = 1 group of organizational and technological solutions

= 2 group of organiz ational and technological solutions

Fig. 4. comparative schedule of equipment loading by month: a) group of $\mathrm{CNC}$ lathes, b) group of CNC milling machines, C) group of universal lathes, d) group of universal milling machines

Based on the simulation results, it can be concluded that the organizational and technological decisions made have led to an increase in the equipment load factor and a more balanced load of various equipment, which will certainly increase production efficiency [16].

When analyzing the possibility of manufacturing an additional range of washers at our own facilities, we found a deterioration in the results: production on time fell from $95 \%$ to $77 \%$, and the backlog of the production program was 8 days. The average equipment load factor for the overall simulation period also decreased, due to an increase in the production cycle of output.

Thus, based on the results of modeling the 2nd group of organizational and technological solutions, the possibility of transferring the production of the following groups of purchased components to their own capacities was revealed: pins, keys and nuts. The transfer of washers, taking into account the production of the above-mentioned purchased components groups at their own facilities, will lead to a shift in the timing of the production program.

The main data on the results of the experiments are shown in table 1. this table allows you to analyze how the proposed organizational and technological solutions affect the functioning of the PLS and, based on readiness, choose the most suitable scenario for the enterprise. 
Table 1. Summary table of results of simulation experiments

\begin{tabular}{|c|c|c|c|c|c|c|c|c|c|c|}
\hline \multirow[b]{2}{*}{$\begin{array}{l}\text { Description of the } \\
\text { proposed organizational } \\
\text { and technological } \\
\text { solutions }\end{array}$} & \multirow[b]{2}{*}{ 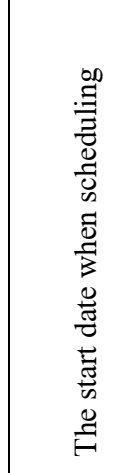 } & \multirow{2}{*}{ 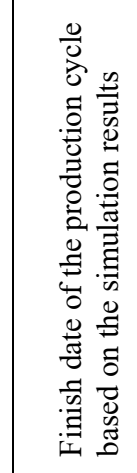 } & \multirow[b]{2}{*}{ 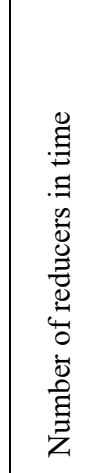 } & \multirow[b]{2}{*}{ 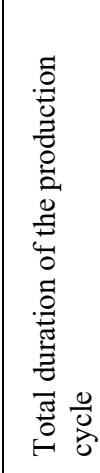 } & \multicolumn{6}{|c|}{$\begin{array}{l}\text { Average equipment load } \\
\text { factor of the equipment } \\
\text { group }\end{array}$} \\
\hline & & & & & 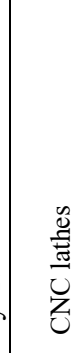 & 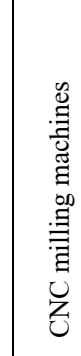 & 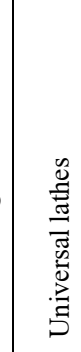 & 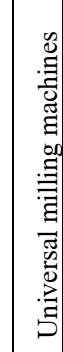 & 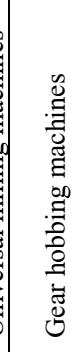 & 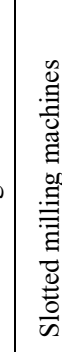 \\
\hline Original version & $\begin{array}{l}14.02 .20 \\
10: 37\end{array}$ & $\begin{array}{l}08.06 .20 \\
16: 27\end{array}$ & 85 & 115,2 & $\begin{array}{l}65,7 \\
\%\end{array}$ & $\begin{array}{l}24,9 \\
\%\end{array}$ & $\begin{array}{l}14,5 \\
\%\end{array}$ & \begin{tabular}{|l|}
2 \\
9 \\
$\%$
\end{tabular} & $\begin{array}{l}10,3 \\
\%\end{array}$ & $\begin{array}{l}6, \\
2 \\
\%\end{array}$ \\
\hline \multicolumn{11}{|c|}{1 group of organizational and technological solutions } \\
\hline $\begin{array}{l}\text { 1.1. Alternative routes: } \\
\text { converting CNC lathes to } \\
\text { universal ones as an } \\
\text { alternative }\end{array}$ & $\begin{array}{l}04.03 .2 \\
010: 24\end{array}$ & $\begin{array}{l}05.06 .2 \\
014: 20\end{array}$ & 91 & 93,2 & $\begin{array}{l}41,0 \\
\%\end{array}$ & $\begin{array}{l}25,1 \\
\%\end{array}$ & $\begin{array}{l}48,1 \\
\%\end{array}$ & $\begin{array}{l}2,9 \\
\%\end{array}$ & $\begin{array}{l}10,1 \\
\%\end{array}$ & $\begin{array}{l}6,4 \\
\%\end{array}$ \\
\hline $\begin{array}{l}\text { 1.2. Modernization: complete } \\
\text { transfer of operations from } \\
\text { gear milling and slotted } \\
\text { milling machines to CNC } \\
\text { milling machines }\end{array}$ & $\begin{array}{l}06.03 .20 \\
10: 37\end{array}$ & $\begin{array}{l}04.06 .20 \\
16: 42\end{array}$ & 95 & 90,3 & $\begin{array}{l}46,1 \\
\%\end{array}$ & $\begin{array}{l}31,5 \\
\%\end{array}$ & $\begin{array}{l}42,3 \\
\%\end{array}$ & $\begin{array}{l}2, \\
9 \\
\%\end{array}$ & $0 \%$ & $\begin{array}{l}0 \\
\%\end{array}$ \\
\hline $\begin{array}{l}\text { 1.3. organizational solution: } \\
\text { transfer of CNC milling } \\
\text { machines to work in } \\
\text { (extended } 2 \text { hours }+ \text { Saturday } \\
6 \text { hours). Plus a change in the } \\
\text { schedule for CNC lathes } \\
\text { (Saturday } 6 \text { hours) }\end{array}$ & $\begin{array}{l}10.02 .20 \\
9: 16\end{array}$ & $\begin{array}{l}04.06 .20 \\
14: 13\end{array}$ & 97 & 115,2 & $\begin{array}{l}58,1 \\
\%\end{array}$ & $\begin{array}{l}44,3 \\
\%\end{array}$ & $\begin{array}{l}58,6 \\
\%\end{array}$ & $\begin{array}{l}2 \\
95 \\
\%\end{array}$ & $0 \%$ & $\begin{array}{l}0 \\
\%\end{array}$ \\
\hline \multicolumn{11}{|c|}{2 group of organizational and technological solutions } \\
\hline $\begin{array}{l}\text { 2.1. Translation into own } \\
\text { power: pin }\end{array}$ & $\begin{array}{l}10.02 .2 \\
010: 06 \\
\end{array}$ & $\begin{array}{l}04.06 .2 \\
014: 15 \\
\end{array}$ & 97 & 115,2 & \begin{tabular}{|l|}
58,1 \\
$\%$
\end{tabular} & \begin{tabular}{|l|}
44,5 \\
$\%$
\end{tabular} & \begin{tabular}{|l|}
58,9 \\
$\%$
\end{tabular} & \begin{tabular}{|l|}
2,9 \\
$5 \%$ \\
\end{tabular} & $0 \%$ & $0 \%$ \\
\hline $\begin{array}{l}\text { 2.2. Translation on its own } \\
\text { power: pin, nut }\end{array}$ & $\begin{array}{l}06.02 .20 \\
14: 02\end{array}$ & $\begin{array}{l}04.06 .20 \\
15: 06\end{array}$ & 96 & 119,0 & $\begin{array}{l}59,6 \\
\%\end{array}$ & $\begin{array}{l}45,7 \\
\%\end{array}$ & $\begin{array}{l}61,4 \\
\%\end{array}$ & $\begin{array}{l}19 \\
6 \\
\% \\
\end{array}$ & $0 \%$ & 0 \\
\hline $\begin{array}{l}\text { 2.3. Translation into own } \\
\text { power: pin, nut, key }\end{array}$ & $\begin{array}{l}06.02 .20 \\
13: 52\end{array}$ & $\begin{array}{l}04.06 .20 \\
16: 32\end{array}$ & 95 & 119,1 & $\begin{array}{l}60,6 \\
\%\end{array}$ & $\begin{array}{l}44,4 \\
\%\end{array}$ & $\begin{array}{l}60,8 \\
\%\end{array}$ & $\begin{array}{c}40 \\
1 \\
\%\end{array}$ & $0 \%$ & $\begin{array}{l}0 \\
\%\end{array}$ \\
\hline $\begin{array}{l}\text { 2.4. Translation into own } \\
\text { power: pin, nut, key, washer }\end{array}$ & $\begin{array}{l}04.02 .20 \\
8: 04\end{array}$ & $\begin{array}{l}11.06 .20 \\
8: 58\end{array}$ & 77 & 128,0 & $\begin{array}{l}61,2 \\
\%\end{array}$ & $\begin{array}{l}42,1 \\
\%\end{array}$ & $\begin{array}{l}58,1 \\
\%\end{array}$ & $\begin{array}{l}37 \\
9 \\
\% \\
\end{array}$ & $0 \%$ & 0 \\
\hline $\begin{array}{l}\text { 2.5. Shift planned production } \\
\text { time }\end{array}$ & $\begin{array}{l}04.02 .20 \\
8: 04\end{array}$ & $\begin{array}{l}11.06 .20 \\
8: 58\end{array}$ & 100 & 128,0 & $\begin{array}{l}61,2 \\
\%\end{array}$ & $\begin{array}{l}42,1 \\
\%\end{array}$ & $\begin{array}{l}58,1 \\
\%\end{array}$ & $\begin{array}{l}37 \\
9 \\
\% \\
\end{array}$ & $0 \%$ & $\begin{array}{l}0 \\
\%\end{array}$ \\
\hline
\end{tabular}

\section{Conclusion}

The PlantTwin simulation system considered in this paper is a tool for simulation of discrete production, which allows solving a wide range of tasks, such as: 
- assessment of the adequacy of the production capacity of the enterprise's PLS for the implementation of the production program

- determination and justification of the composition of technological equipment required for the implementation of a given production program

- verification of production plans and schedules using simulation

- scenario analysis of options for industrial cooperation of enterprises

- analyze the behavior of the production system and develop organizational and technological recommendations to improve efficiency

In addition to the basic functionality for conducting simulation, the PlantTwin system has a built-in planning module that allows you to create a production schedule using several algorithms and then analyze their reachability through simulation.

On the basis of the PlantTwin simulation software package, a simulation model of the PLS of the gearbox manufacturing enterprise was developed. When building a simulation model of the enterprise, a large number of parameters were taken into account, such as: the organizational and technological structure of the enterprise, the company's work schedules, PPR schedules, purchased components, purchase schedules, statistics of equipment failures, product transportation, work under the cooperative scheme, etc [17-19].

The developed simulation model was used to analyze the current possibility of making an order at the enterprise and identify the risks of non-fulfillment of the production plan. The analysis of simulation results allowed us to form a number of organizational and technological proposals and recommendations [15]. By gradually changing the initial model, the proposed solutions were checked and various scenarios were obtained that involve making organizational and technological changes to the enterprise's PLS, depending on its readiness.

Using the example of the developed simulation model, it was clearly shown that APS planning systems do not take into account a number of factors (transportation, reliability of the technological system (emergency failures), failure of the delivery period from suppliers, different execution times of a standardized operation, etc.), which can critically affect the implementation of the production plan and subsequently lead to failure of the set deadlines for the production of final products. In turn, simulation systems can take these factors into account when conducting simulations $[3,7,20]$.

Thus, the operation of operational planning systems in close conjunction with simulation systems will allow you to verify the production schedule, conduct a comprehensive analysis of the PLS, and assess the probability of non-fulfillment of the production order. In addition, the use of simulation systems allows you to check organizational and technological proposals and recommendations for changing the PLS. In addition, the use of simulation systems will improve the quality of technological preparation of production of machine-building enterprises by supporting decision-making as verification of proposals for changing the PLS [21].

This research was funded by Ministry of Science and Higher Education of the Russian Federation, Grant No. 0707-2020-0025.

\section{References}

1. Gujral Barry, Kotthaus Martina, Lakshmipathy Uma, McNicoll Andrew, CardonaTorres Raul, Sandhu Rupninder, Goedecke Michael, Giselbrecht Karlheinz, The role of computer simulation modeling in product/process optimization, Monatshefte für Chemie - Chemical Monthly Vol. 150(5). (2019) 
2. A.A. Malkhanov, V.E. Chernenko. From a simulation model to a digital twin: analysis of the experience of implementing commercial projects, Simulation modeling. Theory and practice, pp 37-46 (2019)

3. A. A. Kutin, V. A. Dolgov, A. A. Kabanov, M. I. Sedykh and S. S. Ivashin Competitive-resource information model of the machine building manufacturing system, IOP Conf. Ser.: Mater. Sci. Eng. Vol 448012008 (2018)

4. Xuechu Zhu, Fei Qiao and Qiushi Cao Industrial big data-based scheduling modeling framework for complex manufacturing system, Advances in Mechanical Engineering Vol. 9(8) pp. 1-12 (2017)

5. P.A. Nikishechkin, N.Yu. Chervonnova, A.N. Nikich. Approach to the construction of specialized portable terminals for monitoring and controlling technological equipment, MATEC Web Conf. Volume 224, pp.1-9 (2018)

6. A.A. Kutin, V.A. Dolgov, M.I. Sedykh, Information Links between Product Life Cycles and Production System Management in Designing of Digital Manufacturing, Procedia CIRP, Volume 41, (2016)

7. S.N. Grigoriev, G.M. Martinov, An ARM-based Multi-channel CNC Solution for Multi-tasking Turning and Milling Machines, Procedia CIRP, 46, pp. 525-528 (2016)

8. A.A. Kutin, V.A. Dolgov, A.A. Kabanov et al, Improving the efficiency of CNC machine tools with multi-pallet systems in machine-building manufacturing, IOP Conference Series-Materials Science and Engineering, Vol. 448, No. UNSP 012010, (2018)

9. P.A. Nikishechkin, N.S. Grigoriev, N.Yu. Chervonnova. Construction of a specialized control system for brush machine and rounding the cutting edges of a metal cutting tool, MATEC Web of Conferences, Vol. 298, p. 00064. EDP Sciences. (2019)

10. S.N. Grigoriev, D.A. Masterenko, V.I. Teleshevskii, P.N. Emelyanov, Contemporary state and outlook for development of metrological assurance in the machine-building industry. Measurement Techniques, 55(11), pp. 1311-1315 (2013)

11. A.V. Isaev, V.A. Grechishnikov, P.M. Pivkin, et. al. Machining of Thin-walled Parts Produced by Additive Manufacturing Technologies, Procedia CIRP, 41, pp. 10231026, (2016).

12. N.M. Bobrovskij, P.A. Melnikov, S.N. Grigoriev, I.N. Bobrovskij, Simulation of thermal fields using different types of wide burnishing, IOP Conf. Ser.: Mater. Sci. Eng. 91012034 (2015)

13. S.N. Grigoriev, G.M. Martinov, Scalable open cross-platform kernel of PCNC system for multi-axis machine tool, Procedia CIRP, 1(1), pp. 238-243 (2012)

14. M.A. Volosova, S.N. Grigor'ev, V.V. Kuzin, Effect of Titanium Nitride Coating on Stress Structural Inhomogeneity in Oxide-Carbide Ceramic. Part 4. Action of Heat Flow. Refract Ind Ceram 56, pp. 91-96 (2015)

15. I.A. Kovalev, M.S. Babin, P.A. Nikishechkin. Development of a method for the determination and registration of unauthorized data transmission channels at industrial manufactories, MATEC Web of Conferences, Vol. 298, p. 00110. EDP Sciences (2019)

16. V.V. Kuzin, S.N. Grigor'ev, M.A. Volosova, Effect of a TiC Coating on the StressStrain State of a Plate of a High-Density Nitride Ceramic Under Nonsteady Thermoelastic Conditions, Refract. Ind. Ceram. 54, pp. 376-380 (2014)

17. A.V. Isaev, V.A. Grechishnikov, P.M. Pivkin, Yu.V. Ilyukhin, M.P. Kozochkin, P.Yu. Peretyagin, Structure and machinability of thin-walled parts made of titanium alloy powder using electron beam melting technology, Journal of Silicate Based and Composite Materials 68(2) pp. 46-50 (2016). 
18. V.V. Kuzin, S.N. Grigoriev, M.Yu. Fedorov, Role of the thermal factor in the wear mechanism of ceramic tools. Part 2: Microlevel, J. Frict. Wear. 36(1), pp. 40-44 (2015)

19. S.N. Grigoriev, G.M. Martinov, The Control Platform for Decomposition and Synthesis of Specialized CNC Systems, Proc. CIRP 41, pp. 858-863 (2016)

20. S.N. Grigoriev, G.M. Martinov, Research and development of a cross-platform CNC kernel for multi-axis machine tool, Proc. CIRP 14, pp. 517-522 (2014).

21. I. A. Kovalev, P. A. Nikishechkin and A. S. Grigoriev. Approach to programmable controller building by its main modules synthesizing based on requirements specification for industrial automation. International Conference on Industrial Engineering, Applications and Manufacturing (ICIEAM), St. Petersburg, pp.1-4 (2017) 